\title{
Hygrothermal characterization of gfrp laminates subjected to different water conditions
}

\author{
P. Sampath Rao ${ }^{1}$, M. Manzoor Husain ${ }^{2}$, D.V. Ravi Shankar ${ }^{3}$ \\ 1. Research scholar JNT University Hyderabad. Mechanical Engineering Department Vijay Rural Engg. \\ College, Nizamabad A.P.INDIA \\ 2. Professor, Mechanical Engineering Department JNT University Hyderabad. A.P.INDIA \\ 3. Professor \& Principal, Nizam Institute of Engineering and Technology, Hyderabad. A.P. INDIA
}

\begin{abstract}
Fibre composites are being used in various applications from aerospace, military, marine boats and submarine to renewable energy generation. Higher energy demands across the developed and growing world for the usage and replacement of conventional materials with polymer composite materials for engineering applications which is always questioned by the end user, unless the research oriented reliable supporting certification is made available. The reinforcement materials are highly hygroscopic, the matrix material provides protection to the reinforcement. Since the edges of parts made of composite materials are exposed to environment, water molecules travels along the reinforcement and cause damage to the interfacial bonding, further the performance of the composite laminate gets effected. In this scenario, the investigation related to this aspect requires quantitative assessment which is carried out with accelerated simulation of the real time situation to provide a scope to characterization of Glass fibre reinforced polymer composite (GFRP) laminates subjected to variable water conditions. This investigation is to study the combined effect of related parameters, moisture salt and temperature. The test results reveal that strength degradation by moisture absorption and temperature effect over the lifecycle of GFRP composite exposed to water and temperature for a long period.
\end{abstract}

Keywords: Glass fibre reinforced polymer composite (GFRP), Resin transfer moulding (RTM), Hygrothermal ageing, retention ratio, flexural modulus.

\section{Introduction}

Glass fiber reinforced composite materials are low cost, light-weight, better mechanical properties, free from health hazard, and thus have the potential for aircraft, automobile and similar structural applications. Carbon, Glass and Kelvar are the most commonly used composite materials in aerospace industry. The effects of moisture on retention of mechanical properties of glass fiber reinforced composites during long-term environmental exposure to moist conditions are very crucial for industrial applications.

With reference to the work related to accelerated environmental ageing study of polyester/glass fibre reinforced composites [3], the results are indicating similar phenomena of delamination in the composite laminates. They studied dynamic mechanical analysis, for a range of temperatures and frequencies under tensile and three-point bending loadings, which revealed that the aged materials gained in stiffness, whereas a small deterioration in strength was found in our work accelerated environmental ageing is set up by constant temperature water bath. Tensile and flexural strength of bamboo fibre reinforced polypropylene composite and bamboo-glass fibre reinforced polypropylene hybrid composite were reduced [5]. On similar way experimental work has been done with polyester-glass fibre reinforced composites. The environmental stress cracking failure due to temperature and moisture has been studied for glass fibre reinforced composites [6]. Moisture does not only affect the adhesive bond of the bonded system in service, but also during the application of FRP on concrete surface. Tests on CFRP bonded to concrete with initially damp surface using a modified cantilever beam indicated reduction in bond strength when compared to specimens with initially dry concrete surface [7]. Since the failure under effect of moisture generally occurs by either concrete delamination or concrete-epoxy interface separation. The effects of variable moisture conditions on the fracture toughness of concrete/FRP bonded system are studied by means of the peel and shear fracture toughness determined from the conditioned test specimens. Moisture conditions can result in strength degradation [8]. The objective of this work is to investigate experimentally the effects of hydrothermal aging environmental conditions on the performance and durability of glass fibre reinforced polymer materials. For this number of specimens are prepared and exposed to accelerated hydrothermal environmental conditions. To know the changes of material properties due to water absorption at room temperature and elevated temperature. For this series of experiments are conducted and results are interpreted to know behaviour of the 
materials. Also the relation between load verses deflection curves are prepared to evaluate flexural modulus of material.

\subsection{Production of laminates using RTM}

\section{EXPERIMENTAL SETUP}

The Resin transfer molding (RTM) machine, a closed mould process, consists of resin injection equipment, it has a hollow cylinder fitted with pressure gauge, valve and pressure pump and mould plates. Glass fibre mats are placed between the mould plates and clamped before sending the resin. A lowviscosity thermo set resin is injected under moderate pressures about 30-40 psi into the mould through injection equipment as shown in fig. 1. The mould get filled with resin under pressure and thus penetrates into all surfaces of fiber, care is taken to avoid defects like blow holes and cavities in the laminates.

In the mould the composite materials get cured due to heat generated by reactions in the resin as it is mixed with accelerator and catalyst. See that all the parts are tightly sealed before sending the resin through pressure pump. This exothermic reaction of the resin will be sufficient for producing laminates with proper curing. Now slowly releasing the bottom valve of the cylinder, the pressurized chemical resin enters in to the mould. Now it is spread equally in to all direction.

To get a well-shaped laminate, allow the mould for 4 to 5 hours for curing. If laminate is solidified then unseal the mould and separate the lower and upper mould parts, the composite laminate is obtained as shown figure-2.

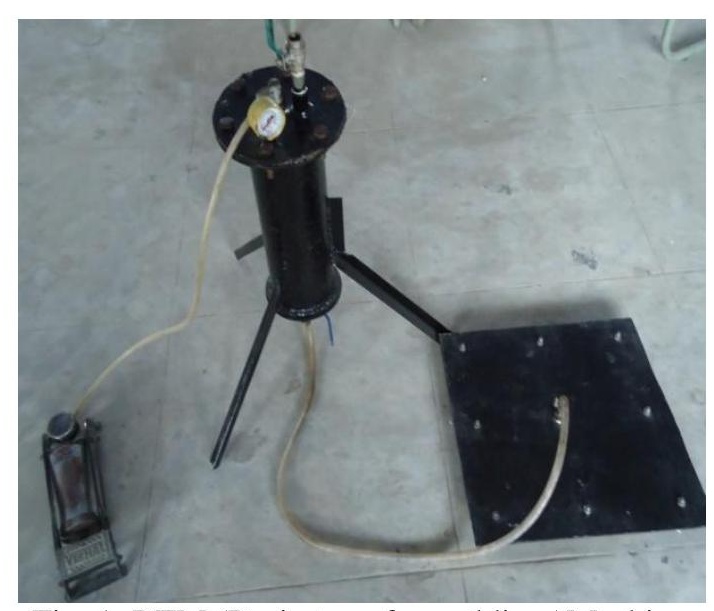

Fig. 1: RTM (Resin transfer molding )Machine

\subsection{Testing of the Laminates}

The laminates obtained by RTM process are 300mm X 300mm X 8mm as shown in the fig. 2. From that standard specimen of dimensions $250 \mathrm{~mm}$ X $30 \mathrm{~mm}$ X $8 \mathrm{~mm}$ are prepared, fig.3. Some of specimens thus prepared are exposed in water at room temperature for 6 months and some of them are exposed to constant temperature $\left(45^{\circ} \mathrm{C}\right)$ in water bath and in salt bath using a furnace with constant temperature control system as shown in fig.4, for a period of 60 days. At every 30 days few specimens are taken from water bath at room temperature and at every 10 days few specimens are taken from constant temperature water bath and salt bath then these specimens taken for mechanical testing. Flexural properties are evaluated by conducting three point bending test, fig. 6 . 


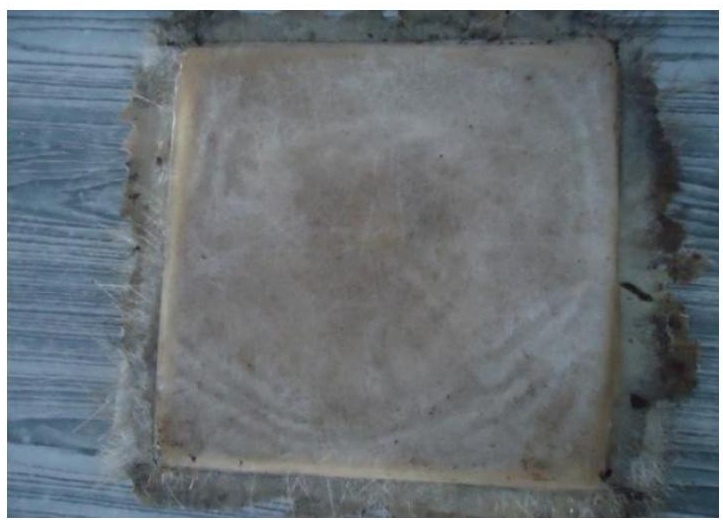

Fig. 2: Composite laminate piece

From the test results load and deflection curve are prepared and calculate the flexural modulus using equation 1.

$$
E_{f}=\frac{L^{3} m}{4 b d^{3}}
$$

$L=$ Support span (Specimen gauge length), (mm)

$b=$ Width of test specimen $(\mathrm{mm})$

$d=$ Depth or Thickness of test specimen (mm)

$m=$ The gradient (i.e., slope) of the initial straight-line portion of the load deflection curve, $(\mathrm{P} / \mathrm{D}),(\mathrm{N} / \mathrm{mm})$.

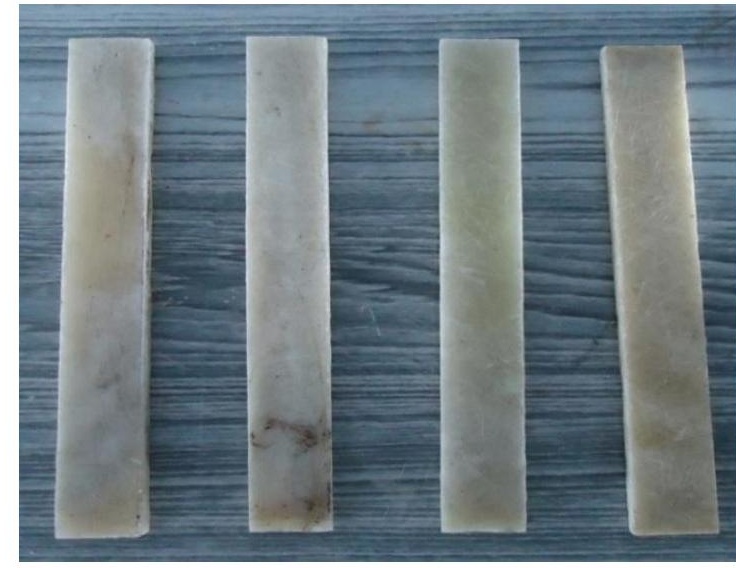

Fig. 3 pieces of laminate produced

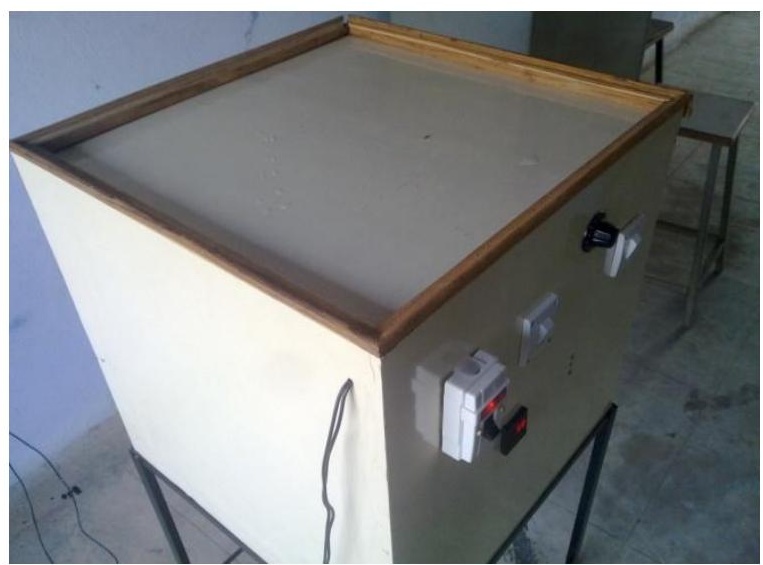

Fig.4 Constant temperature water bath 


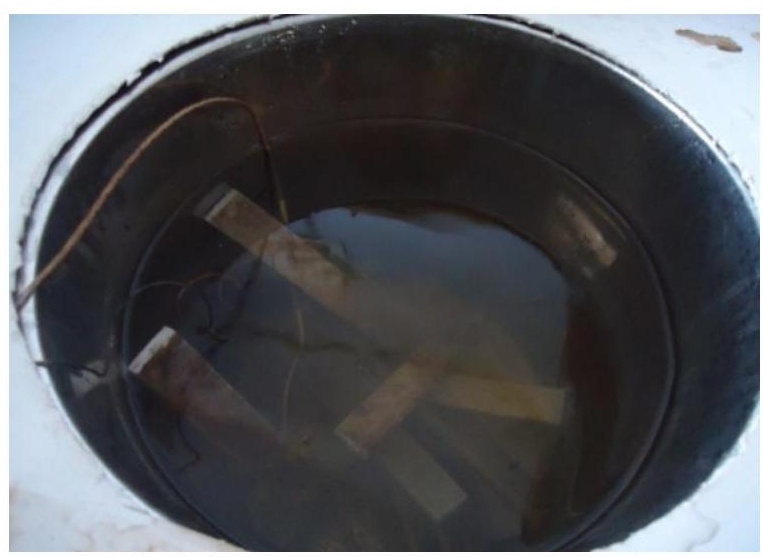

Fig.5 Constant temperature water bath

Specimen size: Specimen Length $=250 \mathrm{~mm}$

Specimen Gauge Length $=220 \mathrm{~mm}$,

Width $b=30 \mathrm{~mm}$, Depth or Thickness $\mathrm{d}=8 \mathrm{~mm}$

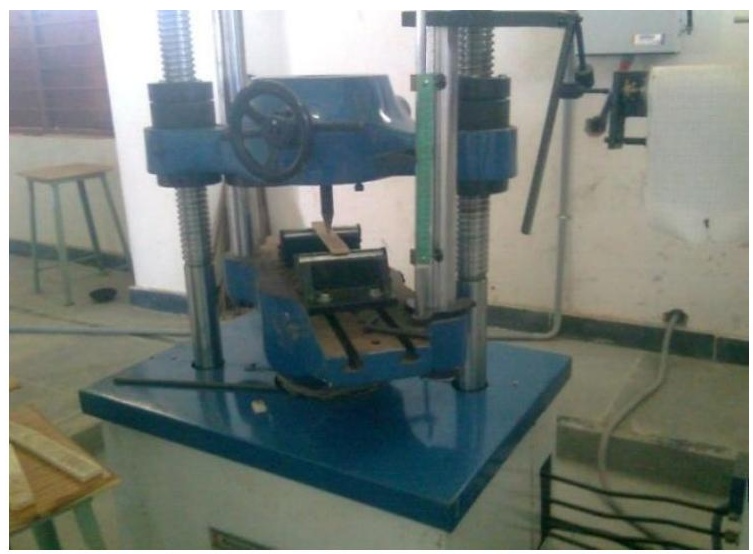

Fig.6: Three point bending test

\subsection{Specimen exposed at room temperature}

The laminates prepared of composite material are exposed to water bath at room temperature, and are tested with three-point bending test. This is repeated for every 30 days and the results are noted (AnuxureTable1.1)and the same displayed in graphs 1.

\subsection{Specimens exposed at constant temperature water bath}

The laminates prepared of composite material are exposed to water bath at constant temperature $45^{0} \mathrm{C}$, and the same are tested with three-point bending test. This is repeated for every 10 days and the results are noted (AnuxureTable1.2)and the same plotted in graphs 2.

\subsection{Specimens exposed at constant temperature salt water bath:}

In this experiment the laminates prepared of composite material are exposed to salt water bath with specific gravity of 1.1 at constant temperature $45^{\circ} \mathrm{C}$, and are tested with three-point bending test. This is repeated for every 10 days and the results (AnuxureTable1.3)are taken for plotting the graphs, as shown in graphs 3. 


\section{RESULTS AND DISCUSSIONS:}

This work focuses on the investigation of the effect of environmental impact on GFRP composite laminates under different moisture and temperature (water bath) conditions. The test results are analysed and the relations of load verses deflection are plotted at various water salinity conditions as discussed above. From the test results, it is clear that flexural modulus of the composite material exposes to environmental conditions changes rapidly at aging of 10 to 30 days and after that shown moderate reduction over the period of 60 days. In the same way the aging condition specimens are found that the significant reduction in flexural modulus due to the strength degradation by moisture absorption and temperature effect as given in the table 1. It is observed that the flexural modulus is decreased to some extent with the presence of moisture and temperature. Strains are parallel and transverse to the fibres at functional failure (leakage) showed a little variation in the presence of moisture and temperature. The more water damage is apparent in the matrix and at the fibre-matrix interfaces where there is less resin adhesion to the fibres with increasing exposure time. Fibre strength is also negatively affected, possibly due to either leaching out of the glass fibres interface layer or glass fibre embrittlement, less effective bonding and load distribution at the fibre-matrix interface.

The retention ratio (ratio of exposed specimen modulus to unexposed specimen modulus) is calculated for exposed specimens at different exposure times as shown in table 1 . The graphs $6 \& 7$ show that retention ratio steadily decreases for the sample exposed for a period of 40 days and further. The retention ratio has been decreased slowly for specimens which are exposed in simple water and salt water at constant temperature $45^{\circ} \mathrm{C}$. It rapidly decreases for the first 90 days which are exposed in water at room temperature.

Typical failure modes observed in test specimens are shown in fig.7, it has been shown that presence of moisture and temperature at the fibre-matrix interface and reduces the strength of the composite material. Thus moisture generally affects any property which is dominated by the matrix and/or interface. However the flexural strength being a fibre dominated property the strength reduction occurs only if the fibres themselves are affected by hydrothermal environmental conditions. It has been shown that water can cause degradation at fibre level in glass fibres. Degradation is initiated by water extracting ions from the fibre, thereby altering its structure and leads to premature failure of the fibres.

Graphs 1: Three- point bending test- specimen exposed room temperature in water bath
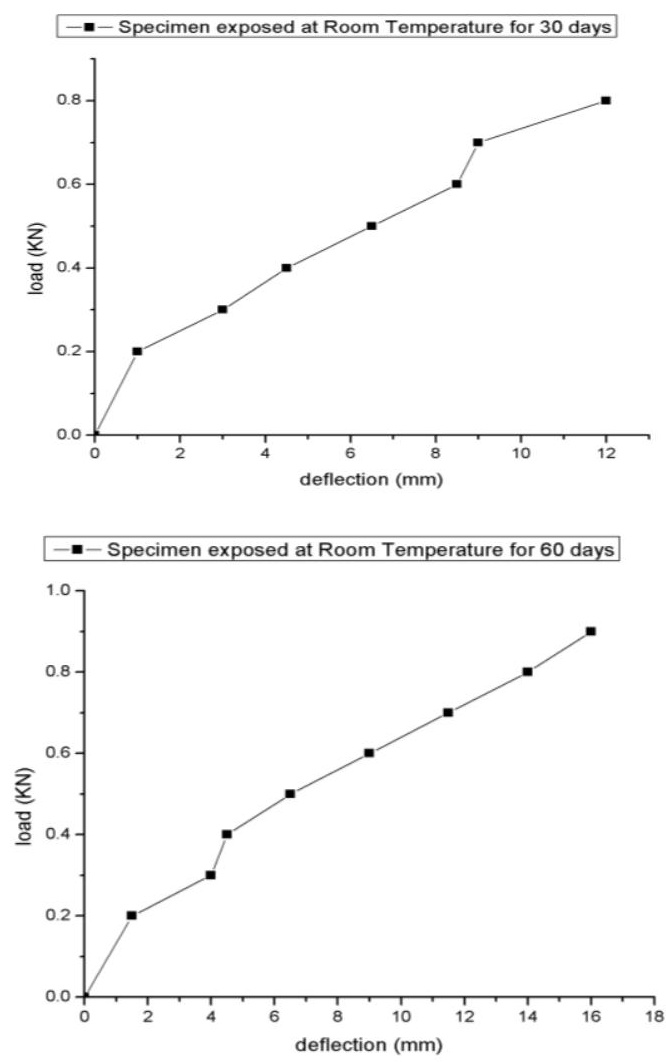

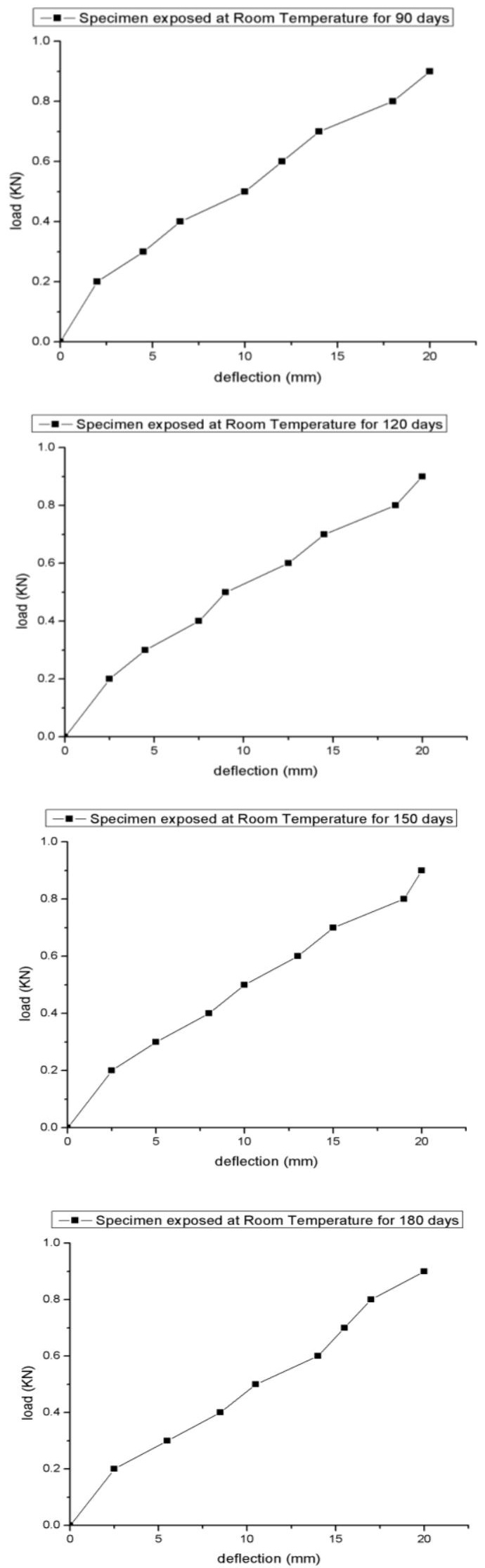

Graphs 2: Three- point bending test- specimen exposed at $45^{\circ} \mathrm{c}$ constant temperatures in water bath www.iosrjournals.org 

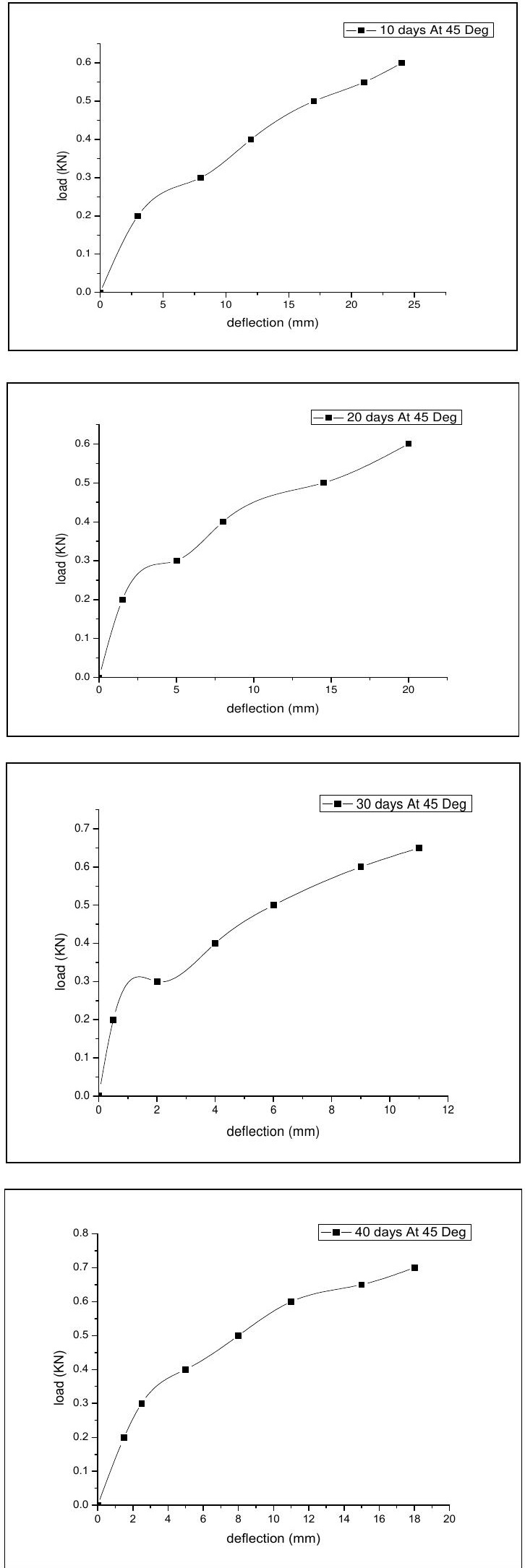

www.iosrjournals.org 

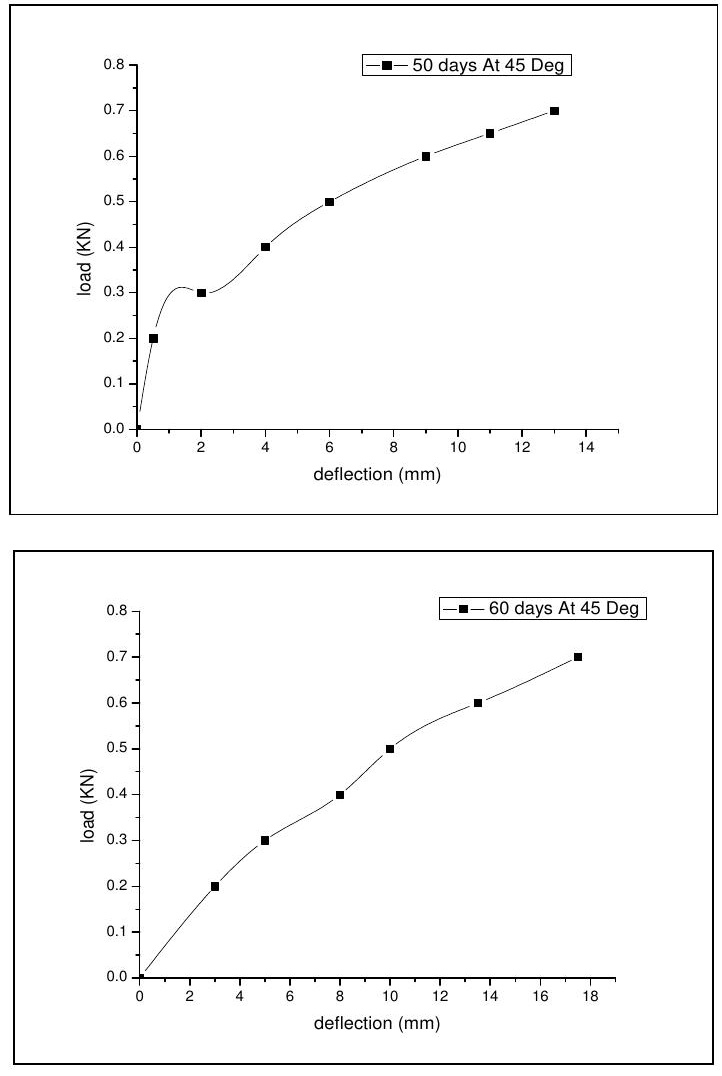

Graphs 3: Three- point bending test- specimen exposed at $45^{\circ} \mathrm{c}$ constant temperatures in salt water bath.
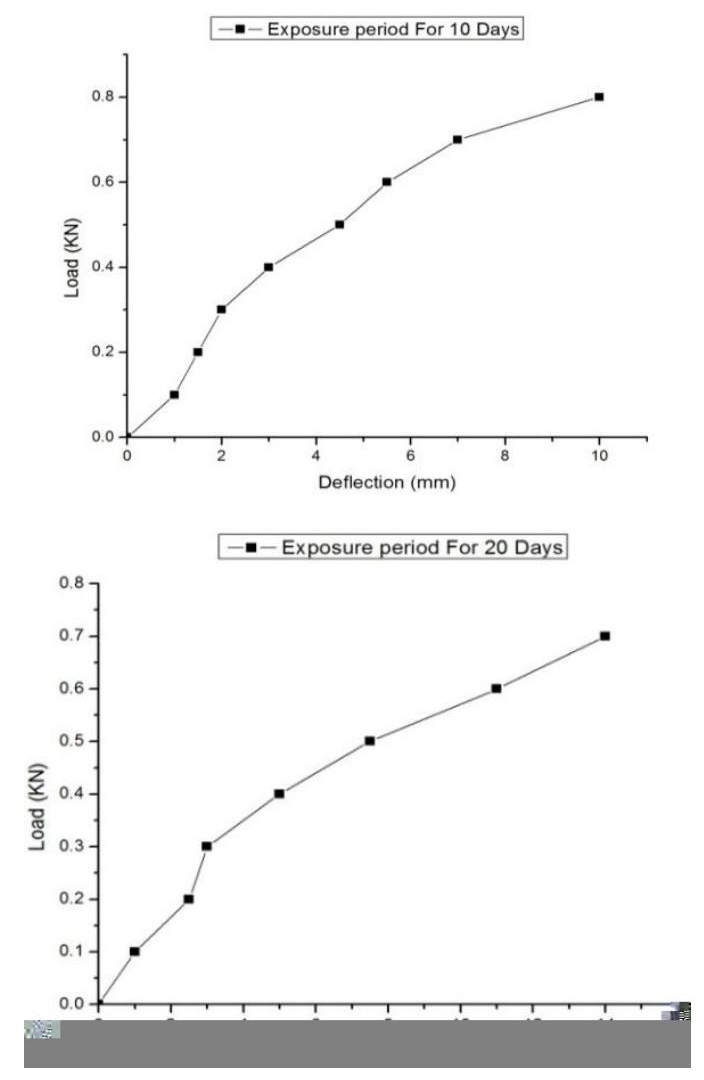


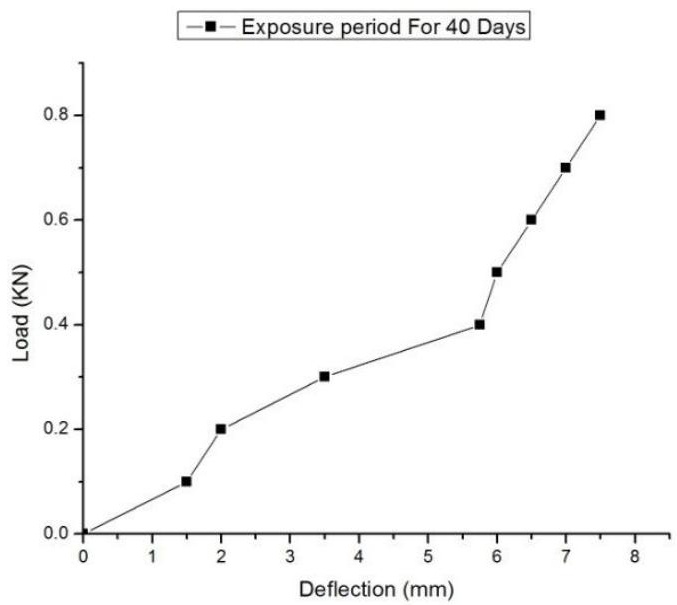

$d=$ Depth or Thickness of test specimen $(\mathrm{mm})$

$m=$ The gradient (i.e., slope) of the initial straight-line portion of the load deflection curve, (P/D), (N/mm).

$$
\begin{aligned}
& \text { Slope }(\mathrm{m})=\Delta \mathrm{Y} / \Delta \mathrm{X} \\
& =0.08 / 0.4 \\
& \mathrm{~m}=0.05 * 10^{3} \\
& \begin{aligned}
E_{f} & =\mathrm{L}^{3} * \mathrm{~m} / 4 \mathrm{bd}^{3} \\
E_{f 1} & =220^{3} * 0.0475 * 10^{3} / 4 * 30 * 8^{3} \\
& =8.232 \mathrm{Gpa}
\end{aligned}
\end{aligned}
$$

\begin{tabular}{|c|c|c|c|c|c|c|c|c|c|}
\hline \multicolumn{10}{|c|}{ Un exposed specimen flexural modulus $=11.553 \mathrm{Gpa}$} \\
\hline \multirow[b]{2}{*}{$\dot{\vartheta}_{\dot{i}}$} & \multicolumn{3}{|c|}{$\begin{array}{l}\text { Specimen in water at Room } \\
\text { Temperature }\end{array}$} & \multicolumn{3}{|c|}{$\begin{array}{l}\text { Specimen in water at constant } \\
\text { Temperature } 45^{\circ} \mathrm{C}\end{array}$} & \multicolumn{3}{|c|}{$\begin{array}{l}\text { Specimen in salt water at } \\
\text { constant Temperature } 45^{\circ} \mathrm{C}\end{array}$} \\
\hline & $\begin{array}{c}\text { Exposu } \\
\text { re } \\
\text { Time } \\
\text { (Days) }\end{array}$ & $\begin{array}{c}\text { Flexural } \\
\text { modulus } \\
(\mathrm{Gpa})\end{array}$ & $\begin{array}{l}\text { Retentio } \\
\text { n Ratio }\end{array}$ & $\begin{array}{l}\text { Exposure } \\
\text { Time } \\
\text { (Days) }\end{array}$ & $\begin{array}{c}\text { Flexural } \\
\text { modulus } \\
\text { (Gpa) }\end{array}$ & $\begin{array}{l}\text { Retention } \\
\text { Ratio }\end{array}$ & $\begin{array}{l}\text { Exposure } \\
\text { Time } \\
\text { (Days) }\end{array}$ & $\begin{array}{c}\text { Flexural } \\
\text { modulu } \\
\mathrm{s} \\
(\mathrm{Gpa})\end{array}$ & $\begin{array}{l}\text { Retentio } \\
\text { n Ratio }\end{array}$ \\
\hline 1 & 30 & 8.665 & 0.75 & 10 & 8.566 & 0.74 & 10 & 8.232 & 0.71 \\
\hline 2 & 60 & 6.932 & 0.60 & 20 & 7.798 & 0.68 & 20 & 7.365 & 0.64 \\
\hline 3 & 90 & 6.672 & 0.58 & 30 & 6.932 & 0.60 & 30 & 6.498 & 0.56 \\
\hline 4 & 120 & 6.499 & 0.56 & 40 & 5.799 & 0.50 & 40 & 5.777 & 0.50 \\
\hline 5 & 150 & 6.157 & 0.53 & 50 & 4.332 & 0.38 & 50 & 4.077 & 0.36 \\
\hline 6 & 180 & 5.776 & 0.50 & 60 & 3.466 & 0.30 & 60 & 3.009 & 0.26 \\
\hline
\end{tabular}

Table 1: Flexural modulus of Composite material subjected to various water conditions 


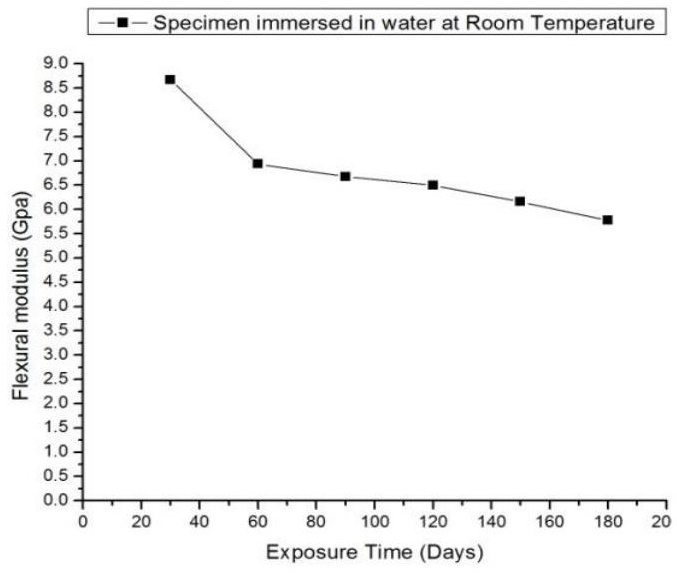

Graph 4: Time v/s Flexural modulus retention ratio at room temperature

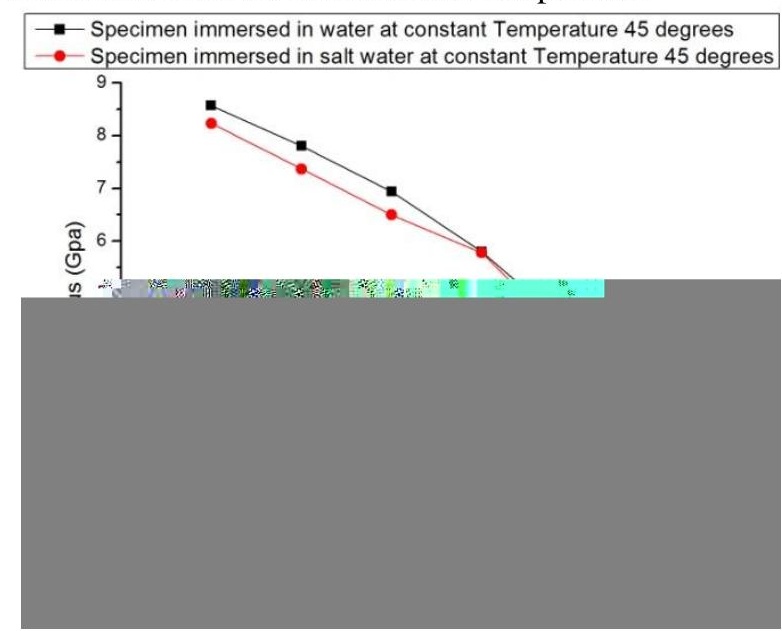

Graph 5: Time v/s Flexural modulus at constant temperature $45^{\circ} \mathrm{C}$

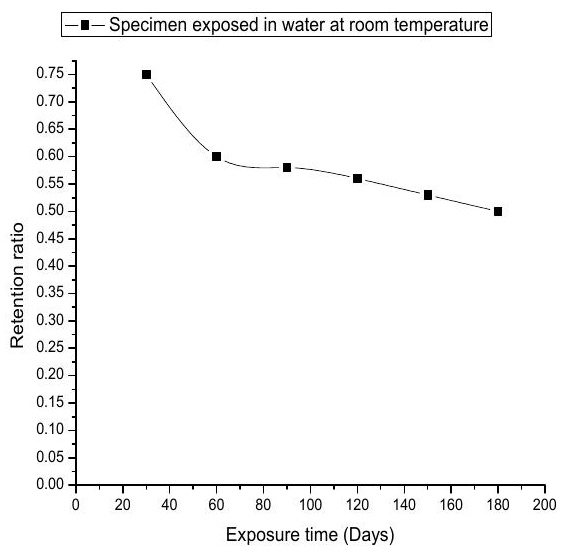


Graph 6: Time v/s retention ratio at room temperature

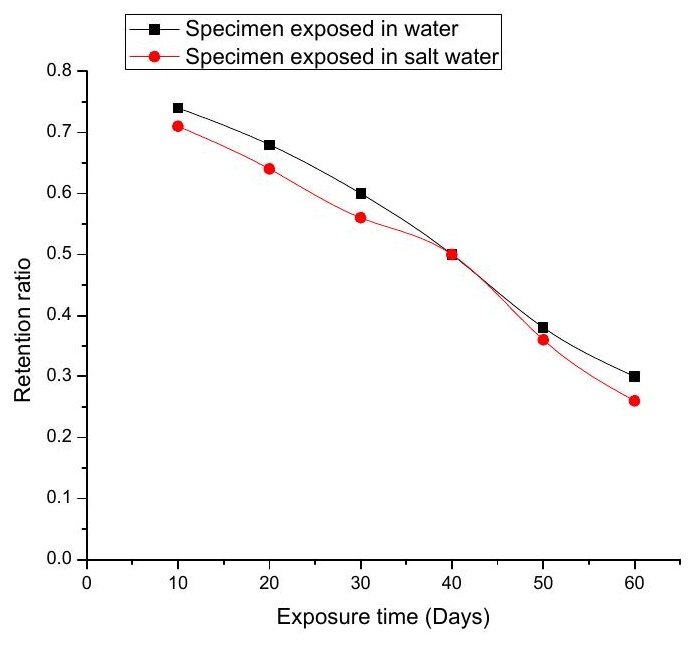

Graph 7: Time v/s retention ratio at constant temperature $45^{\circ} \mathrm{C}$

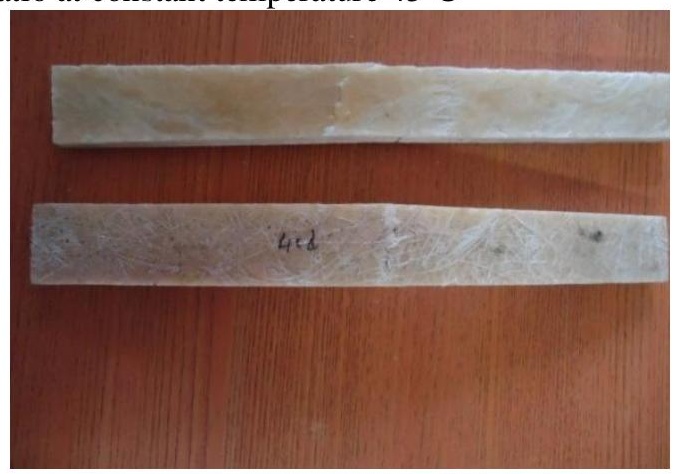

Fig 7: Figure shows failure behaviour of the composite materials after 3-point bending test

\section{CONLUSIONS:}

The experimental investigation is showed a remarkable reduction in mechanical strength (flexural modulus) of GFRP Composites which are exposed to different water salinity and at constant temperature for different exposure periods. From the test results, it is clear that flexural modulus of the specimens is significantly reduced due to the degradation of GFRP under the environmental hydrothermal ageing conditions at $45^{\circ} \mathrm{C}$ where in simple water, strength decreases up to $26 \%$ to $70 \%$ and in salt water strength decreases up to $29 \%$ to $74 \%$ for the period of 2 months, but aging at room temperature strength decreases up to $25 \%$ to $50 \%$ for period of 6 months. As per the results, the retention ratio initially has rapid reduction and then gradually decreases over a long period of exposure to water salinity and expects to maintain considerable minimum strength. The following points are drawn from test results during this study.

i. In Composite materials, the moisture absorption is more in glass fibre materials.

ii. The presence of moisture or water particles in the matrix, fibre-matrix interface of composite materials attack on the glass fibres are the reason for the reduction of mechanical properties.

iii. To the flexural modulus reduction, the temperature is a key factor for accelerated aging in the processes of water diffusion and degradation.

iv. Prolonged exposure to the environment of moisture condition can result in significant degradation of the GFRP bond strength.

v. It is worth noticing that aging at elevated temperatures strength degradation is more in salt water exposure compared to simple water. 


\section{REFERENCES:}

[1] Mechanical testing of advanced fibre composites J M Hodgkinson Wood Head Publishng Limited.

[2] Springer G.S.,Environmental ffects on Composite materials Vol.2 (1984), Lancaster PA:Technomic publishing co.inc.

[3] Dionysis E. Mouzakis Helen Zoga and Costas Galiotis "Accelerated environmental ageing study of polyester/glass fibre reinforced composites (GFRPCs)-2007.

[4] Environmental effects on bamboo-glass-polypropylene hybrid composites Moe Moe KinLiao 38 (2003) 363- 376.

[5] The "Durability of bamboo-glass fiber reinforced polymer matrix hybrid composites" by author MOE MOE THWE, KIN LIO publised in journal of Composites Science and Technology 63 (2003) 375387

[6] The environmental stress corrosion cracking of glass fibre-reinforced laminates and single E-glass filaments by author F.R.JONES. J.W.ROCK, J.E.BAILEY (19833)1059-1071

[7] Wan B, Petrou MF, Harries KA. The effects of the presence of water on the durability of bond between CFRP and concrete. J Reinf Plast Composites 2006; 25(8):875-90.

[8] C.Tukta and O.Buyukozturk on the "Deterioration of FRP/concrete bond system under variable moisture conditions quantified by fracture mechanic Composites: PartB 42(2011)145-154 Elsevier.

[9] Nishizaki and Meiarashi,S (2002) Long term Deteration GFRP in Water and Moist Environment Journal of Composite for Construction, Vol.6 NO.1 PP21-27.

\section{ANUXURE}

Table1.1:Three-point bending test Results -Specimen exposed at Room Temperature

\begin{tabular}{|c|c|c|c|c|c|c|c|c|c|c|c|c|}
\hline \multirow[b]{3}{*}{ S.No } & \multicolumn{12}{|c|}{ Exposure period } \\
\hline & \multicolumn{2}{|c|}{30 days } & \multicolumn{2}{|c|}{60 days } & \multicolumn{2}{|c|}{90 days } & \multicolumn{2}{|c|}{120 days } & \multicolumn{2}{|c|}{150 days } & \multicolumn{2}{|c|}{180 days } \\
\hline & 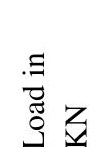 & 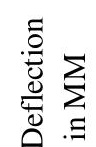 & 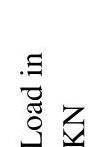 & 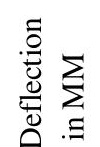 & 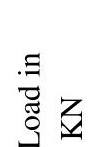 & 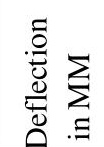 & $\stackrel{\Xi}{\Xi}$ & 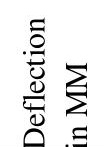 & 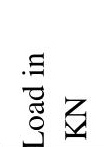 & 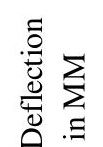 & 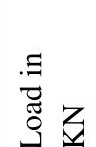 & 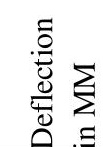 \\
\hline 1 & 0 & 0 & 0 & 0 & 0 & 0 & 0 & 0 & 0 & 0 & 0 & 0 \\
\hline 2 & 0.2 & 1 & 0.2 & 1.5 & 0.2 & 2 & 0.2 & 2.5 & 0.2 & 2.5 & 0.2 & 2.5 \\
\hline 3 & 0.3 & 3 & 0.3 & 4 & 0.3 & 4.5 & 0.3 & 4.5 & 0.3 & 5.0 & 0.3 & 5.5 \\
\hline 4 & 0.4 & 4.5 & 0.4 & 4.5 & 0.4 & 6.5 & 0.4 & 7.5 & 0.4 & 8.0 & 0.4 & 8.5 \\
\hline 5 & 0.5 & 6.5 & 0.5 & 6.5 & 0.5 & 10 & 0.5 & 9 & 0.5 & 10.0 & 0.5 & 10.5 \\
\hline 6 & 0.6 & 8.5 & 0.6 & 9 & 0.6 & 12 & 0.6 & 12.5 & 0.6 & 13.0 & 0.6 & 14.0 \\
\hline 7 & 0.7 & 9 & 0.7 & 11.5 & 0.7 & 14 & 0.7 & 14.5 & 0.7 & 15.0 & 0.7 & 15.5 \\
\hline 8 & 0.8 & 12 & 0.8 & 14 & 0.8 & 18 & 0.8 & 18.5 & 0.8 & 19.0 & 0.8 & 17.0 \\
\hline 9 & & & 0.9 & 16 & 0.9 & 20 & 0.9 & 20 & 0.9 & 20 & & \\
\hline
\end{tabular}

Table1.2: Three-point bending test results -specimen exposed at $45^{\circ} \mathrm{c}$ constant temperature water bath

\begin{tabular}{|l|l|l|l|l|l|l|}
\hline \multirow{2}{*}{ S.No } & \multicolumn{6}{|c|}{ Exposure period } \\
\cline { 2 - 7 } & 10 days & 20 days & 30 days & 40 days & 50 days & 60 days \\
\hline
\end{tabular}




\begin{tabular}{|c|c|c|c|c|c|c|c|c|c|c|c|c|}
\hline & 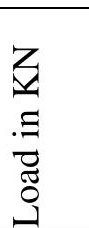 & 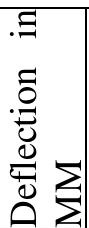 & 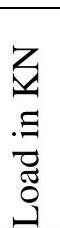 & 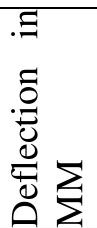 & 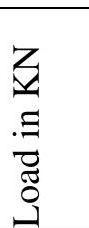 & 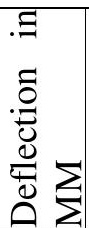 & 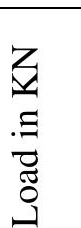 & 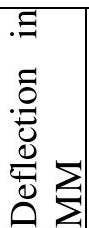 & 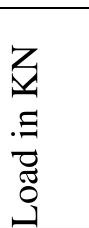 & 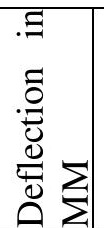 & 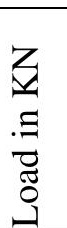 & 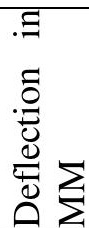 \\
\hline 1 & 0 & 0 & 0 & 0 & 0 & 0 & 0 & 0 & 0 & 0 & 0 & 0 \\
\hline 2 & 0.2 & 3 & 0.2 & 1.5 & 0.2 & 0.5 & 0.2 & 1.5 & 0.2 & 0.5 & 0.2 & 3 \\
\hline 3 & 0.3 & 8 & 0.3 & 5 & 0.3 & 2 & 0.3 & 2.5 & 0.3 & 2 & 0.3 & 5 \\
\hline 4 & 0.4 & 12 & 0.4 & 8 & 0.4 & 4 & 0.4 & 5 & 0.4 & 4 & 0.4 & 8 \\
\hline 5 & 0.5 & 17 & 0.5 & 14.5 & 0.5 & 6 & 0.5 & 8 & 0.5 & 6 & 0.5 & 10 \\
\hline 6 & 0.55 & 21 & 0.6 & 20 & 0.6 & 9 & 0.6 & 11 & 0.6 & 9 & 0.6 & 13.5 \\
\hline 7 & 0.6 & 24 & - & - & 0.65 & 11 & 0.65 & 15 & 0.65 & 11 & 0.7 & 17.5 \\
\hline 8 & - & - & - & - & - & - & 0.7 & 18 & 0.7 & 13 & - & - \\
\hline
\end{tabular}

Table 1.3: Three-point bending test results -specimen exposed at $45^{\circ} \mathrm{c}$ constant temperature salt water bath

\begin{tabular}{|c|c|c|c|c|c|c|c|c|c|c|c|c|}
\hline \multirow[t]{3}{*}{ S.No } & \multicolumn{12}{|c|}{ Exposure period } \\
\hline & \multicolumn{2}{|c|}{10 days } & \multicolumn{2}{|c|}{20 days } & \multicolumn{2}{|c|}{30 days } & \multicolumn{2}{|c|}{40 days } & \multicolumn{2}{|c|}{50 days } & \multicolumn{2}{|c|}{60 days } \\
\hline & 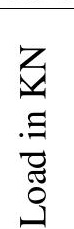 & 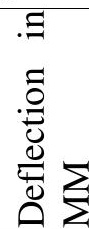 & 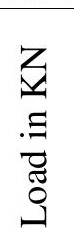 & 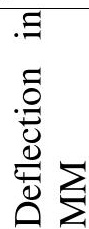 & 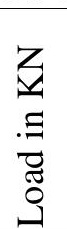 & 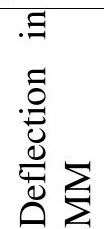 & 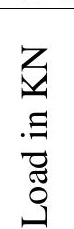 & 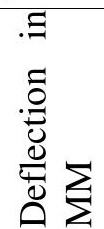 & 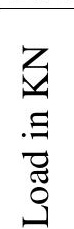 & 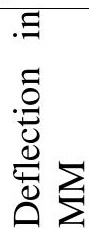 & 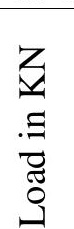 & 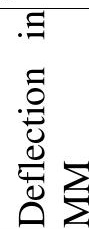 \\
\hline 1 & 0 & 0 & 0 & 0 & 0 & 0 & 0 & 0 & 0 & 0 & 0 & 0 \\
\hline 2 & 0.1 & 1 & 0.1 & 1 & 0.1 & 1 & 0.1 & 1.5 & 0.1 & 2.0 & 0.1 & 2.0 \\
\hline 3 & 0.2 & 1.5 & 0.2 & 2.5 & 0.2 & 2.75 & 0.2 & 2 & 0.2 & 2.5 & 0.2 & 2.75 \\
\hline 4 & 0.3 & 2 & 0.3 & 3 & 0.3 & 3.5 & 0.3 & 3.5 & 0.3 & 3.5 & 0.3 & 3.5 \\
\hline 5 & 0.4 & 3 & 0.4 & 5 & 0.4 & 5.5 & 0.4 & 5.75 & 0.4 & 4.5 & 0.4 & 5.0 \\
\hline 6 & 0.5 & 4.5 & 0.5 & 7.5 & 0.5 & 7 & 0.5 & 6.0 & 0.5 & 5.0 & 0.5 & 5.5 \\
\hline 7 & 0.6 & 5.5 & 0.6 & 11 & 0.6 & 8.5 & 0.6 & 6.5 & 0.6 & 6.5 & 0.6 & 6.5 \\
\hline 8 & 0.7 & 7 & 0.7 & 14 & 0.7 & 11 & 0.7 & 7.0 & 0.7 & 7.5 & 0.7 & 8.5 \\
\hline 9 & 0.8 & 10 & & & 0.8 & 12 & 0.8 & 7.5 & 0.8 & 9 & 0.8 & 9.0 \\
\hline
\end{tabular}




\begin{tabular}{|c|c|c|c|c|c|c|c|c|c|c|c|c|}
\hline & 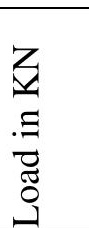 & 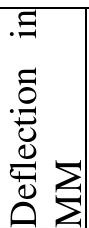 & 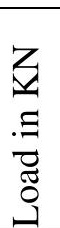 & 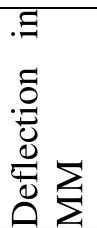 & 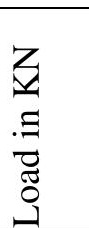 & 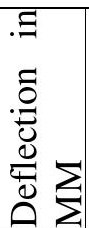 & 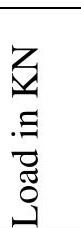 & 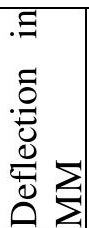 & 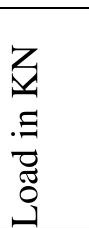 & 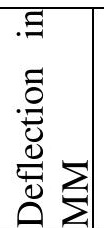 & 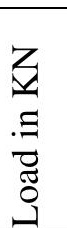 & 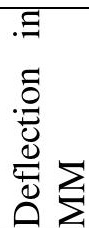 \\
\hline 1 & 0 & 0 & 0 & 0 & 0 & 0 & 0 & 0 & 0 & 0 & 0 & 0 \\
\hline 2 & 0.2 & 3 & 0.2 & 1.5 & 0.2 & 0.5 & 0.2 & 1.5 & 0.2 & 0.5 & 0.2 & 3 \\
\hline 3 & 0.3 & 8 & 0.3 & 5 & 0.3 & 2 & 0.3 & 2.5 & 0.3 & 2 & 0.3 & 5 \\
\hline 4 & 0.4 & 12 & 0.4 & 8 & 0.4 & 4 & 0.4 & 5 & 0.4 & 4 & 0.4 & 8 \\
\hline 5 & 0.5 & 17 & 0.5 & 14.5 & 0.5 & 6 & 0.5 & 8 & 0.5 & 6 & 0.5 & 10 \\
\hline 6 & 0.55 & 21 & 0.6 & 20 & 0.6 & 9 & 0.6 & 11 & 0.6 & 9 & 0.6 & 13.5 \\
\hline 7 & 0.6 & 24 & - & - & 0.65 & 11 & 0.65 & 15 & 0.65 & 11 & 0.7 & 17.5 \\
\hline 8 & - & - & - & - & - & - & 0.7 & 18 & 0.7 & 13 & - & - \\
\hline
\end{tabular}

Table 1.3: Three-point bending test results -specimen exposed at $45^{\circ} \mathrm{c}$ constant temperature salt water bath

\begin{tabular}{|c|c|c|c|c|c|c|c|c|c|c|c|c|}
\hline \multirow[t]{3}{*}{ S.No } & \multicolumn{12}{|c|}{ Exposure period } \\
\hline & \multicolumn{2}{|c|}{10 days } & \multicolumn{2}{|c|}{20 days } & \multicolumn{2}{|c|}{30 days } & \multicolumn{2}{|c|}{40 days } & \multicolumn{2}{|c|}{50 days } & \multicolumn{2}{|c|}{60 days } \\
\hline & 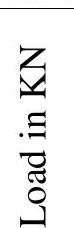 & 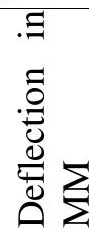 & 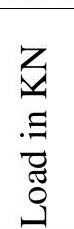 & 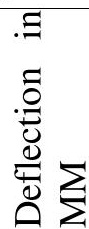 & 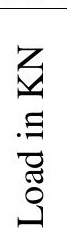 & 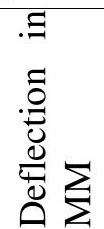 & 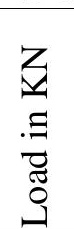 & 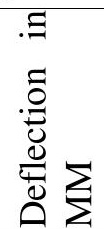 & 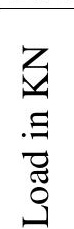 & 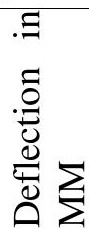 & 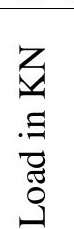 & 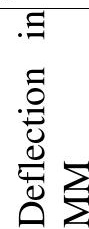 \\
\hline 1 & 0 & 0 & 0 & 0 & 0 & 0 & 0 & 0 & 0 & 0 & 0 & 0 \\
\hline 2 & 0.1 & 1 & 0.1 & 1 & 0.1 & 1 & 0.1 & 1.5 & 0.1 & 2.0 & 0.1 & 2.0 \\
\hline 3 & 0.2 & 1.5 & 0.2 & 2.5 & 0.2 & 2.75 & 0.2 & 2 & 0.2 & 2.5 & 0.2 & 2.75 \\
\hline 4 & 0.3 & 2 & 0.3 & 3 & 0.3 & 3.5 & 0.3 & 3.5 & 0.3 & 3.5 & 0.3 & 3.5 \\
\hline 5 & 0.4 & 3 & 0.4 & 5 & 0.4 & 5.5 & 0.4 & 5.75 & 0.4 & 4.5 & 0.4 & 5.0 \\
\hline 6 & 0.5 & 4.5 & 0.5 & 7.5 & 0.5 & 7 & 0.5 & 6.0 & 0.5 & 5.0 & 0.5 & 5.5 \\
\hline 7 & 0.6 & 5.5 & 0.6 & 11 & 0.6 & 8.5 & 0.6 & 6.5 & 0.6 & 6.5 & 0.6 & 6.5 \\
\hline 8 & 0.7 & 7 & 0.7 & 14 & 0.7 & 11 & 0.7 & 7.0 & 0.7 & 7.5 & 0.7 & 8.5 \\
\hline 9 & 0.8 & 10 & & & 0.8 & 12 & 0.8 & 7.5 & 0.8 & 9 & 0.8 & 9.0 \\
\hline
\end{tabular}

